\title{
Diversity of Veronaea botryosa from different hosts and evaluation of laboratory challenge models for phaeohyphomycosis in Acipenser transmontanus
}

\author{
Esteban Soto $^{1, *}$, Christine Richey ${ }^{1}$, Stephen R. Reichley ${ }^{2}$, Brittany Stevens ${ }^{1}$, \\ Kirsten V. Kenelty ${ }^{1}$, Janiee Lewis ${ }^{1}$, Barbara Byrne ${ }^{3}$, Nathan P. Wiederhold ${ }^{4}$, \\ Thomas B. Waltzek ${ }^{5}$, Matthew F. Sheley ${ }^{3}$, Alvin C. Camus ${ }^{6}$, Matt J. Griffin ${ }^{2}$

\footnotetext{
${ }^{1}$ Department of Medicine and Epidemiology, School of Veterinary Medicine, University of California, Davis, Davis, CA 95616, USA

${ }^{2}$ Department of Pathobiology and Population Medicine, College of Veterinary Medicine, Mississippi State University, Stoneville, MS 38776, USA

${ }^{3}$ Department of Pathology, Microbiology and Immunology, School of Veterinary Medicine, University of California, Davis, 4315 Vet Med 3A, Davis, CA 95616, USA

${ }^{4}$ Fungus Testing Laboratory, Department of Pathology, and Department of Microbiology \& Immunology, University of Texas Health Science Center at San Antonio, San Antonio, TX 78229, USA

${ }^{5}$ University of Florida, College of Veterinary Medicine, Department of Infectious Diseases and Pathology, PO Box 110880 , 2015 SW 16th Avenue, Gainesville, FL 32608, USA

${ }^{6}$ College of Veterinary Medicine, University of Georgia, Athens, GA 30602, USA
}

\begin{abstract}
Veronaea botryosa has been identified as a pathogen of cultured white sturgeon Acipenser transmontanus. In 2015, samples from 19 white sturgeon were received for diagnosis, of which 14 cultured positive for $V$. botryosa. Intraspecific variability among $V$. botryosa isolates from different clinically affected hosts and geographic regions was investigated using repetitive extragenic palindromic PCR fingerprinting (rep-PCR). The rep-PCR profiles of $16 \mathrm{~V}$. botryosa isolates from a human, sea turtles, and cultured fish were distinct from those of other phaeoid fungi belonging to the genera Cladophialophora and Exophiala. To gain a better understanding of the pathogenesis of $V$. botryosa mycosis, 5 laboratory challenge methods were evaluated in white sturgeon fingerlings. Intramuscular (IM) and intracoelomic (IC) injection challenges produced cumulative mortalities of $13.3 \%(8 / 60)$ and $3.3 \%(2 / 60)$, respectively, and $V$. botryosa was recovered from $100 \%(10 / 10)$ of dead fingerlings. Affected fish exhibited abnormal orientation and/or failure to maintain neutral buoyancy, emaciation, coelomic distension, exophthalmos, cutaneous erythema, and ulcerated skin. After $6 \mathrm{wk}$, surviving fish were euthanized, and samples of liver were taken for mycological evaluation. Viable fungus was detected in $90 \%$ and $100 \%$ of fish surviving IM and IC challenge, respectively. No $V$. botryosa-associated mortality was detected in other groups challenged by immersion, immersion with abrasion, or orally. Both IM and IC challenge routes appear suitable for the induction of $V$. botryosa infection in white sturgeon and can serve as models for the study of disease pathogenesis associated with this emergent pathogen.
\end{abstract}

KEY WORDS: Fungus $\cdot$ Mycosis $\cdot$ Sturgeon $\cdot$ Veronaea

Resale or republication not permitted without written consent of the publisher

\section{INTRODUCTION}

Sturgeons (Osteichthyes: Acipenseridae) represent 25 species of anadromous and potamodromous fishes of North America and Eurasia, with an evolutionary history of over 100 million yr (Trifonov et al. 2016).
They are cultured in many countries due to their considerable economic and ecologic value. Sturgeon aquaculture is important, as many wild populations have been drastically depleted by overfishing, habitat destruction, and pollution (Pikitch et al. 2005, Monterey Bay Aquarium 2016). In the western USA, stur- 
geon culture is a multi-million dollar industry, and the production of high-quality caviar has made sturgeon roe one of the few aquaculture-generated US exports. In addition, meat is sold locally, nationally, and internationally. Other value-added products from farmed sturgeon include medical and health products, cosmetics, and leather (Wei et al. 2011). In 2012, approximately $1350 \mathrm{t}$ of sturgeon were produced in North America. It is projected that US production may surpass $2200 t$ by the end of 2017, with revenues exceeding US \$20 000000 annually.

White sturgeon iridovirus and acipenserid herpesvirus 2 (AciHV-2) cause significant mortality in cultured white sturgeon. In addition, systemic phaeohyphomycosis caused by the dematiaceous mold Veronaea botryosa (Chaetothyriales: Herpotrichiellaceae) is an important emergent disease affecting white sturgeon $A$. transmontanus and Siberian sturgeon $A$. baerii aquaculture. The disease, known to producers as 'fluid belly,' causes mortalities in adult animals that result in significant economic losses (Steckler et al. 2014). Associated most commonly with soil and plants, V. botryosa is a phaeoid, saprobic mold and zoonotic pathogen in immunocompromised humans that causes disease in amphibians, reptiles, and fish (Bonifaz et al. 2013, Donnelly et al. 2015, Hosoya et al. 2015, Zhu et al. 2015).

Signs and lesions of $V$. botryosa infection are variable, but can include abnormal buoyancy and orientation, emaciation, coelomic distension, exophthalmos, cutaneous erythema, and skin and eye ulceration. Necropsy findings include serosal petechiation, serosanguinous ascites, organomegaly with nodular and cystic lesions, and greenish serosal plaques. Microscopically, hyphae are present in serosal plaques and can invade most organs in association with angioinvasion. Lesions are a mixture of necrosis, pyogranulomatous inflammation, and occasional granulomas (Steckler et al. 2014). Mortality in 5 to 8 yr old mature females results in economic losses to caviar producers in the western USA. Anecdotal reports from industry representatives estimate losses in California exceeding US \$900000 annually (E. Soto et al. unpubl.).

Although $V$. botryosa has been implicated as a pathogen of cultured sturgeon, controlled laboratory challenges have not been conducted, and disease pathogenesis is poorly understood. Little is known regarding the persistence of $V$. botryosa in the environment, its genetic diversity, or host-related factors, such as tissue predilection sites during early stages of infection. This study was undertaken to evaluate the efficacy of 5 laboratory challenge methods for the induction of systemic phaeohyphomycosis by $V$. botryosa, as well as to establish a reliable model for future studies of disease pathogenesis and evaluation of therapeutic and prophylactic measures. In addition, repetitive extragenic palindromic PCR fingerprinting (rep-PCR) was employed to investigate genetic variability among $V$. botryosa isolates from different hosts and geographical regions.

\section{MATERIALS AND METHODS}

\section{Fungal culture}

In August and September 2015, an aquaculture farm experienced morbidity and mortality in freshwater cultured adult white sturgeon. Samples of liver and spleen from 19 fish were submitted to the UC Davis School of Veterinary Medicine for diagnostic evaluation. Briefly, $5 \mathrm{~mm}$ tissue samples were plated onto potato flake agar (PFA), incubated at $25^{\circ} \mathrm{C}$ for $14 \mathrm{~d}$ in aerobic conditions, and examined for growth. Hyphae and conidia were observed microscopically for morphological description. Fourteen-day old isolates were suspended in sterile water and frozen at $-80^{\circ} \mathrm{C}$ for further use. Other previously identified phaeoid isolates were obtained from archived collections of the UC Davis School of Veterinary Medicine Teaching Hospital and the Texas Health Science Center at San Antonio, Fungus Testing Laboratory (Table 1). Archived isolates were streaked on PFA agar and incubated at $25^{\circ} \mathrm{C}$ for $14 \mathrm{~d}$ in aerobic conditions.

\section{Molecular analysis}

Fungal clones were expanded for 2 wk at $22^{\circ} \mathrm{C}$ on Mueller Hinton agar plates supplemented with $5 \%$ sheep serum. Plates were flooded with $10 \mathrm{ml}$ of sterile nuclease-free $\mathrm{H}_{2} \mathrm{O}$, agitated with a sterile swab, transferred to a $15 \mathrm{ml}$ conical centrifuge tube, and centrifuged at $4000 \times g\left(10 \mathrm{~min}\right.$ at $\left.15^{\circ} \mathrm{C}\right)$. DNA was extracted from the resulting pellet using a PowerSoil ${ }^{\circledR}$ DNA Isolation Kit (Mo BIO Laboratories) following the manufacturer's instructions. Genomic DNA was quantified spectrophotometrically on a NanoDrop $^{\mathrm{TM}} 2000$ (ThermoFisher Scientific) and diluted to approximately $1 \mathrm{ng}^{-1} \mathrm{l}^{-1}$.

The identity of suspected Veronaea botryosa isolates from sturgeon, in addition to archived $V$. botryosa, Cladophialophora, and Exophiala aquamarina isolates from other sources, was confirmed by partial sequencing of the beta-tubulin (tub2) gene using the 
Table 1. Phaeoid fungi used in this study

\begin{tabular}{|c|c|c|c|c|}
\hline Isolate & Species & Host & Year & Location \\
\hline 812064 & Cladophialophora sp. & Koi carp & 2008 & California \\
\hline 1009407 & Exophiala aquamarina & Frog fish & 2010 & California \\
\hline 1006392 & E. aquamarina & Bonita barracuda & 2010 & California \\
\hline 1102537 & E. aquamarina & Green sturgeon & 2011 & California \\
\hline 608911 & Veronaea botryosa & White sturgeon & 2006 & California \\
\hline $11-8844$ & V. botryosa & White sturgeon & 2011 & California \\
\hline 12M06899 & $V$. botryosa & Sturgeon & 2012 & California \\
\hline $15 \mathrm{M} 00828$ & $V$. botryosa & Sturgeon & 2015 & California \\
\hline DI15-136 & $V$. botryosa & Unknown & 2012 & Florida \\
\hline DI15-134 & V. botryosa & Sea turtle & 2007 & Florida \\
\hline DI14-348 & V. botryosa & Sea turtle & 2014 & Florida \\
\hline DI15-135 & V. botryosa & Human & 2014 & California \\
\hline F15-3-4 & V. botryosa & White sturgeon & 2015 & California \\
\hline F15-3-5 & $V$. botryosa & White sturgeon & 2015 & California \\
\hline F15-3-6 & V. botryosa & White sturgeon & 2015 & California \\
\hline F15-3-7 & V. botryosa & White sturgeon & 2015 & California \\
\hline F15-3-8 & V. botryosa & White sturgeon & 2015 & California \\
\hline F15-3-11 & V. botryosa & White sturgeon & 2015 & California \\
\hline F15-3-12 & $V$. botryosa & White sturgeon & 2015 & California \\
\hline F15-3-14 & V. botryosa & White sturgeon & 2015 & California \\
\hline
\end{tabular}

sembled contigs using CLUSTALW (Thompson et al. 1994). The best-fit nucleotide substitution model for phylogenetic analysis was determined using the Bayesian information criterion as the Kimura-2 parameter model (Kimura 1980), assuming a certain fraction of sites are evolutionarily invariable $(\mathrm{K} 2+\mathrm{I})$. Bayesian analysis was performed with Markov chain Monte Carlo searches of 2 simultaneous runs of 4 chains. Chain sampling occurred every $100^{\text {th }}$ tree over 1000000 generations, and the first $25 \%$ were discarded as 'burn-in' with posterior probabilities calculated from the remaining trees.

Rep-PCR fingerprinting was performed on the fungal isolates using primer sets and protocols previously employed for assessing genetic diversity in bacteria (Versalovic et al. 1991,

Bt2a/T2 and T1/T22 primer combinations (Table 2). This resulted in congruent products of $\sim 500$ and $\sim 1400 \mathrm{bp}$, respectively. Purified PCR products were sequenced directly using the same primers used to produce the amplicon (Eurofins MWG Operon). Forward and reverse reads were de novo assembled in Geneious R9.1.4 (Kearse et al. 2012) and deposited in the National Center for Biotechnology Information's (NCBI) GenBank.

Phylogenetic and molecular evolutionary analyses were conducted in MEGA 6.06 and MrBayes v3.2.6 (Huelsenbeck \& Ronquist 2001, Ronquist \& Huelsenbeck 2003, Tamura et al. 2013). Comparable sequences of waterborne molds isolated from aquatic animals and characterized in a previous study (Table 3 ; de Hoog et al. 2011) were downloaded from NCBI's nonredundant nucleotide database and aligned with as-

Table 2. PCR primers used in this study

\begin{tabular}{|c|c|c|}
\hline Primer & Sequence $\left(5^{\prime}-3^{\prime}\right)$ & Reference \\
\hline \multicolumn{3}{|c|}{ Beta-tubulin sequencing } \\
\hline Bt2a & GGT AAC CAA ATC GGT GCT GCT T & Glass \& Donaldson (1995) \\
\hline T1 & AAC ATG CGT GAG ATT GTA AGT & O'Donnell \& Cigelnik (1997) \\
\hline $\mathrm{T} 2$ & TAG TGA CCC TTG GCC CAG TTG & O'Donnell \& Cigelnik (1997) \\
\hline T22 & TCT GGA TGT TGT TGG GAA TCC & O'Donnell \& Cigelnik (1997) \\
\hline \multicolumn{3}{|c|}{ Repetitive extragenic palindromic PCR } \\
\hline ERIC I & ATG TAA GCT CCT GGG GAT TCA C & Versalovic et al. (1991) \\
\hline ERIC II & AAG TAA GTG ACT GGG GTG AGC G & Versalovic et al. (1991) \\
\hline BOX & CTA CGG CAA GGC GAC GCT GAC G & Versalovic et al. (1994) \\
\hline $\mathrm{GTG}_{5}$ & GTG GTG GTG GTG GTG & Versalovic et al. (1994) \\
\hline
\end{tabular}

1994, Griffin et al. 2013, Chou et al. 2014) (Table 2). The $50 \mu$ PCRs were performed on a C1000 Touch thermal cycler (Bio-Rad Laboratories) with previously described cycling parameters for each primer set (Griffin et al. 2013, Chou et al. 2014).

\section{Laboratory-controlled infectious challenges}

To better understand the pathogenesis of $V$. botryosa infection in fish, 5 challenge methods were evaluated in white sturgeon fingerlings ( 6 mo old, 50 g): (1) immersion, (2) immersion with cutaneous mucus removal, (3) intracoelomic injection (IC), (4) intramuscular injection (IM), and (5) oral. Each treatment used 6 replicate 1321 tanks (10 fish $\operatorname{tank}^{-1}$ for a total of 60 fish treatment ${ }^{-1}$ ) receiving $18^{\circ} \mathrm{C}$ fresh water. For each treatment, a similar set of replicate control tanks were not exposed to the fungus. One 2015 sturgeon isolate (F-15-3-5) was grown in PFA as previously described. Fourteen days postinoculation, hyphal and conidia suspensions were collected after flooding the plate with $7 \mathrm{ml}$ of $0.1 \%$ Tween 80 in phosphate buffered saline (PBS) and suspended by agitation with a sterile swab. Viability was confirmed by plating serial dilutions on PFA. 
Table 3. Nucleotide sequences of waterborne molds used to determine phylogenetic placement of suspected Veronaea botryosa recovered from white sturgeon Acipenser transmontanus. Isolates are identified by their respective CBS-KNAW Fungal Biodiversity Centre accession number. Associated metadata were taken from de Hoog et al. (2011). (-) not reported

\begin{tabular}{|c|c|c|c|}
\hline $\begin{array}{l}\text { Species } \\
\text { Isolate (CBS acc. no.) }\end{array}$ & Origin & Geography & GenBank \\
\hline \multicolumn{4}{|l|}{ Exophiala angulospora } \\
\hline 119911 & Weedy seadragon & USA & JN112430 \\
\hline \multicolumn{4}{|l|}{ E. aquamarina } \\
\hline 119918 & Leafy seadragon & USA & JN112434 \\
\hline 119916 & Leafy seadragon & USA & JN112435 \\
\hline 119919 & Leafy seadragon & USA & JN112436 \\
\hline 120407 & Leafy seadragon & USA & JN112437 \\
\hline 119917 & Leafy seadragon & USA & JN112438 \\
\hline 119921 & Weedy seadragon & USA & JN112439 \\
\hline 119912 & Winter flounder & USA & JN112440 \\
\hline 119915 & Little tunny & USA & JN112441 \\
\hline \multicolumn{4}{|l|}{ E. pisciphila } \\
\hline 537.73 & Catfish & USA & JN112493 \\
\hline 119913 & Potbelly seahorse & - & JN112494 \\
\hline 119914 & Potbelly seahorse & - & JN112495 \\
\hline \multicolumn{4}{|l|}{ E. psychrophila } \\
\hline 191.87 & Atlantic salmon & Norway & JN112497 \\
\hline 256.92 & Salmon & Ireland & JN112498 \\
\hline \multicolumn{4}{|l|}{ E. salmonis } \\
\hline 157.67 & Trout & Canada & JN112499 \\
\hline \multicolumn{4}{|l|}{ Veronaea botryosa } \\
\hline 121506 & Human & Japan & JN112502 \\
\hline 101462 & Human & Not provided & JN112503 \\
\hline 102593 & Human & China & JN112504 \\
\hline 254.57 & Sansa olive slag & Italy & JN112505 \\
\hline
\end{tabular}

Fish in the immersion challenge were placed in 101 of static water containing $\sim 10^{5}$ colony-forming units (CFU ml ${ }^{-1}$ ) for $3 \mathrm{~h}$ before water flow was resumed. A similar method was used for fish exposed by immersion following skin mucus removal. Prior to challenge, fish were anesthetized in $100 \mathrm{mg} \mathrm{l}^{-1}$ of buffered tricaine methanesulfonate (MS-222) (Argent Chemical Laboratories), and skin mucus was removed by dragging a paper towel twice, cranially to caudally, along the lateral line and dorsal portions of the coelom. For the IC, IM, and oral challenges, fish were anesthetized as previously described and administered $\sim 10^{4} \mathrm{CFU}_{\text {fish }}^{-1} \mathrm{~V}$. botryosa suspension in sterile water. IC and IM injections were made on the ventral midline near the base of the pelvic fin and $1 \mathrm{~cm}$ dorsal to the lateral line, slightly posterior to the dorsal fin, respectively. For oral challenges, fungal suspension was placed directly into the buccal cavity while physically closing the opercula for $5 \mathrm{~s}$ with the fish out of water. Control fish were administered sterile PBS in a similar manner for each treatment.
Daily morbidity and mortality were recorded for $6 \mathrm{wk}$ post-challenge. Moribund fish, or those presenting signs of abnormal swimming, lethargy, exophthalmia, skin lesions, or coelomic distension, were euthanized with buffered MS-222 (500 $\mathrm{mg} \mathrm{l}^{-1}$ ) and necropsied. Explants of spleen and liver ( 20 mg) were collected and plated on Sabouraud dextrose agar and tryptic soy agar II plates with 5\% sheep's blood (University of California, Biological Media Services). Two IM-challenged whole moribund fish and samples of liver, spleen, and kidney from 6 IM, 1 IC, and 3 immersion-challenged, mucus-removed freshly dead fish were fixed in $10 \%$ neutral buffered formalin, processed by standard methods, and stained with hematoxylin and eosin (H\&E) for light microscopic examination. Select sections were stained by periodic acid-Schiff and Gomori methenamine silver methods.

At the end of the challenge, all fish were euthanized, and 10 fish treatment $^{-1}$ (challenged and controls) were necropsied. Samples of liver $(\sim 5 \mathrm{~mm})$ from 10 fish treatment ${ }^{-1}$ (challenged and controls) were plated onto PFA and incubated at $25^{\circ} \mathrm{C}$ for $14 \mathrm{~d}$ in aerobic conditions for fungal isolation.

\section{RESULTS}

\section{Fungal culture}

Dematiaceous fungi were isolated from 14 of 19 fish sampled in 2015. Colonies were olivaceous and velvety, with a black reverse (Fig. 1). Pale, 2-celled, clavate conidia with rounded apices and truncate bases were produced from dark, geniculate conidiophores, consistent with Veronaea botryosa (Fig. 2). Fungal identity was confirmed molecularly as detailed below.

\section{Molecular analysis}

Direct sequencing reads resulted in contig assemblies ranging from $1226 \mathrm{bp}$ for the Cladophialophora sp. to $1359 \mathrm{bp}$ for the Exophiala aquamarina isolates. 

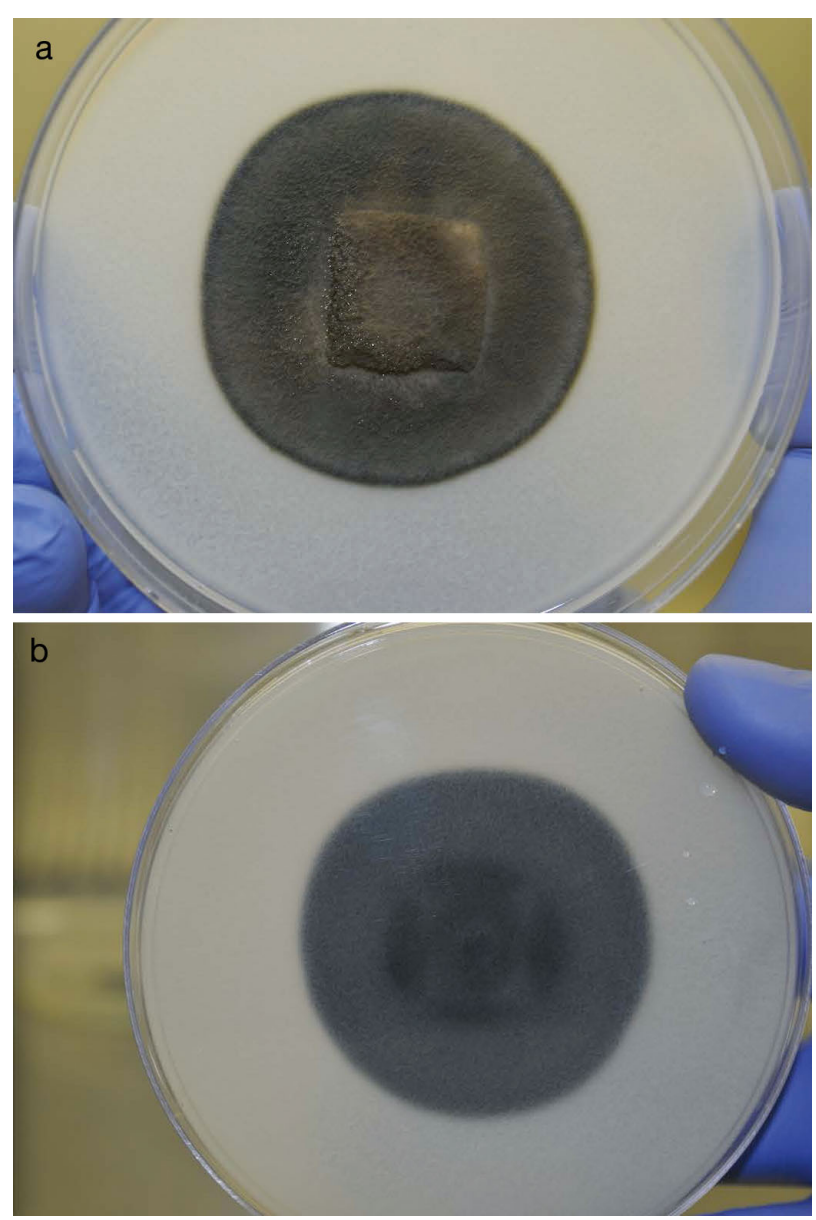

Fig. 1. Veronaea botryosa isolated from spleen of cultured white sturgeon Acipenser transmontanus. The $15 \mathrm{~d}$ old colony is (a) olivaceous and velvety with (b) a black reverse when grown on potato flake agar

Isolates from white sturgeon in California shared 99.9-100\% similarity between themselves and V. botryosa from different sources. Bayesian inference based on tub2 gene fragments confirmed preliminary morphological identification, placing the white sturgeon isolates within a discrete clade containing other $V$. botryosa isolates from a previous study (de Hoog et al. 2011) (Fig. 3). The ERIC I \& II, BOX, GTG ${ }_{5}$, and ERIC II primers generated group-specific profiles that differentiated $V$. botryosa from other phaeoid isolates, with profiles generated by the BOX primer being most informative (Fig. 4). While other primer sets separated $V$. botryosa from the other dematiaceous fungi, profiles generated by the ERIC and GTG $_{5}$ primers demonstrated limited intraspecific variability among the $V$. botryosa isolates. BOX profiles for $V$. botryosa from different hosts and regions were mostly congruent, sharing $>87 \%$ average similarity (range 59.2$99.4 \%$ ), while demonstrating limited similarity to

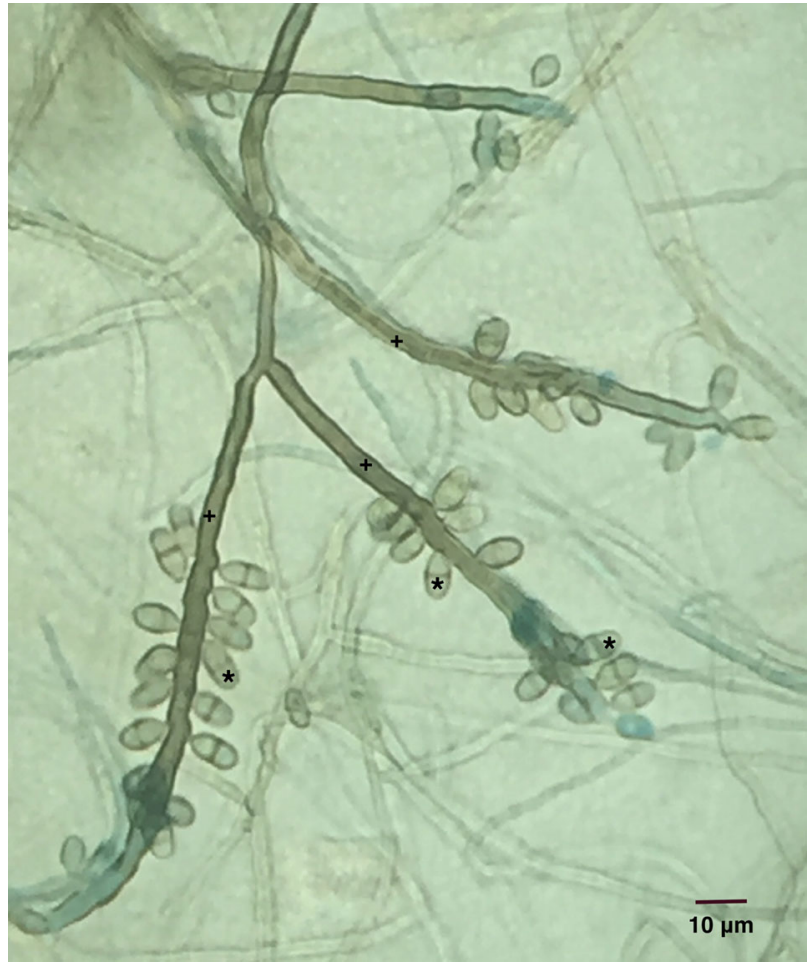

Fig. 2. Veronaea botryosa hyphae and conidia. Pale, 2-celled, clavate conidia $(*)$ with rounded apices and truncate bases arise from dark, geniculate conidiophores (+)

Cladophialophora sp. (range 7.8-11.1\%) and E. aquamarina (range 0-14.2\%). BOX profiles from the California sturgeon isolates possessed a high degree of similarity (range 96.3-99.4\%) and homogeny (range 90.8-97.4\%) with several $V$. botryosa isolates from unknown hosts in California (608911, 11-8844, 12M06899, 15M00828). However, the profiles were disparate (range: 68.7-83.0\%) from a smaller cluster of $V$. botryosa that included an isolate of unknown host origin from Florida, 2 isolates from sea turtles (DI15-134 and DI14-348) in Florida, and a human isolate (DI15-135) from California, suggesting a small degree of intraspecific host- or geographic-based genetic variation. Consistent with phylogenetic inferences derived from tub2, BOX rep-PCR profiles clustered the $V$. botryosa from sturgeon together, within a larger tribe containing $V$. botryosa isolates from different hosts and geographic regions, and separate from E. aquamarina and Cladophialophora sp. (Fig. 5).

\section{Infectious challenges}

Six weeks post-challenge, cumulative mortalities of 3.3 and $13.3 \%$ had occurred in IC- and IM-chal- 
lenged fish, respectively (Table 4, Fig. 6). Affected fish exhibited signs and lesions consistent with those reported by Steckler et al. (2014), including lethargy and abnormal swimming (negative buoyancy), scoliosis, hyphema, and erythematous, primarily ventral, skin. Gross findings included multiple foci of dark pigmentation in the gills, mucohemorrhagic discharge from vents, pale livers, and erythematous distal intestines. Intramuscularly challenged fish had reddened and edematous injection sites that exuded friable purulent-like material. $V$. botryosa was recovered from the livers of all dead fish (2 IC and 8 IM injected) and in $90 \%(9 / 10)$ and $100 \%$ (10/10) of fish surviving the 6 wk IM and IC challenges, respectively.

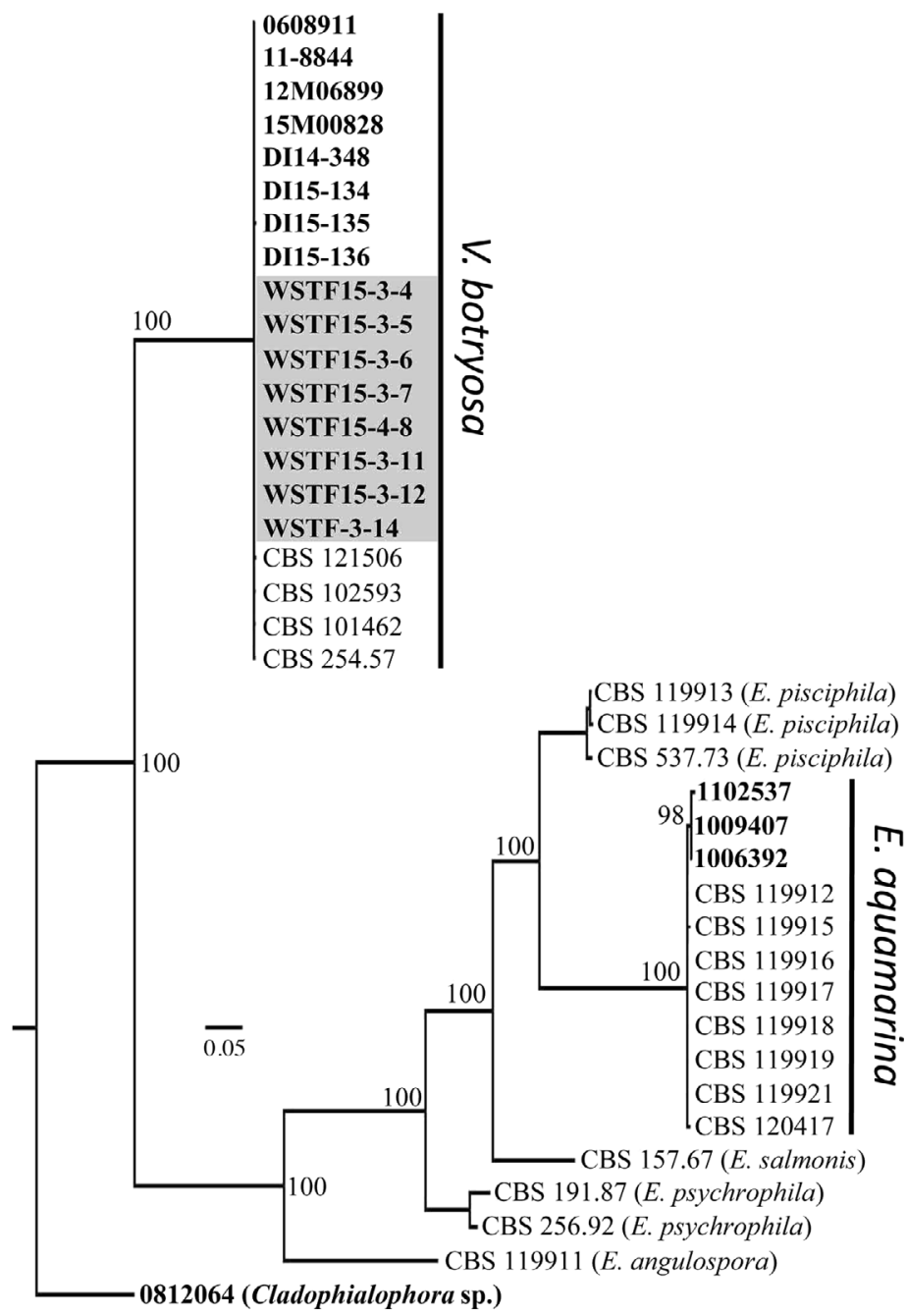

Fig. 3. Bayesian inference tree based for a select panel of aquatic fungi based on partial sequencing of the beta-tubulin gene. Numbers above branches represent posterior probability values. Isolates sequenced in the current study are listed in bold, while isolates recovered from white sturgeon Acipenser transmontanus in California (USA) in 2015 are indicated by grey overlay
Histological changes at IM injection sites varied between the 2 fish examined whole. In one, lesions were confined to epaxial muscle, hypodermis, and dermis, and consisted of large central sheets of macrophages, with scattered multinucleated giant cells, fibroblasts, strands of fibrin-like material, and infrequent pigmented hyphae. Small numbers of lymphocytes and scattered granulocytes formed a narrow peripheral mantle. Inflammatory infiltrates radiated into adjacent muscle, isolating individual and small groups of myofibers. In the second fish, central regions were composed of pale basophilic, mucinous connective tissue, with only patchy, small central collections of inflammatory cells. Hyphae were few in these areas and most common within giant cells. Intense inflammatory infiltrates, as previously described, and large numbers of hyphae extended along fascial planes to envelop and infiltrate the notochord and spinal cord (Fig. 7). Hyphae did not reach the coelomic cavity, although the swim bladder wall was infiltrated in 1 individual.

Lesions in spleens, kidneys, and livers from both groups were few. When present, changes most commonly involved individual or small collections of multinucleated giant cells, small ill-defined collections of macrophages, or combinations of both. Rarely, slightly larger foci of pyogranulomatous inflammation were present in the liver. There was no associated necrosis, and hyphae were rare. In 1 IM-injected fish, multiple hepatic arterial and venous lumens contained hyphae that infiltrated the adjacent parenchyma. Perivascular necrosis and granulomatous inflammation was mild. In 1 IC-injected fish, extensive necrosis, with no hyphae and minimal inflammation, affected an area of mesentery, pancreas, and spleen. Large numbers of hyphae and granulomatous infiltrates permeated the intervening coelomic space and multiple thrombosed mesenteric arteries (Fig. 8).

Morphology of the hyphae and the intensity of pigmentation varied, presumptively due to their age. In actively spreading lesions, hyphae were abundant and pale golden. Most had thin, parallel walls, with less frequent septation and acute angle branching. In more chronic lesions, particularly within multinucleated giant cells, hyphae were often dark bronze, with short plump segments that tapered adjacent to septa, and occasional globose swellings (Fig. 8).

Fish challenged orally exhibited no clinical signs, and no fish died from $V$. botryosa infection. Three fish challenged by immersion with mucus removal, 1 immersion-challenged fish, and 1 control fish for immersion with mucus removal were euthanized due to abnormal swimming and positive buoyancy. No gross pathologic changes were observed, and no 

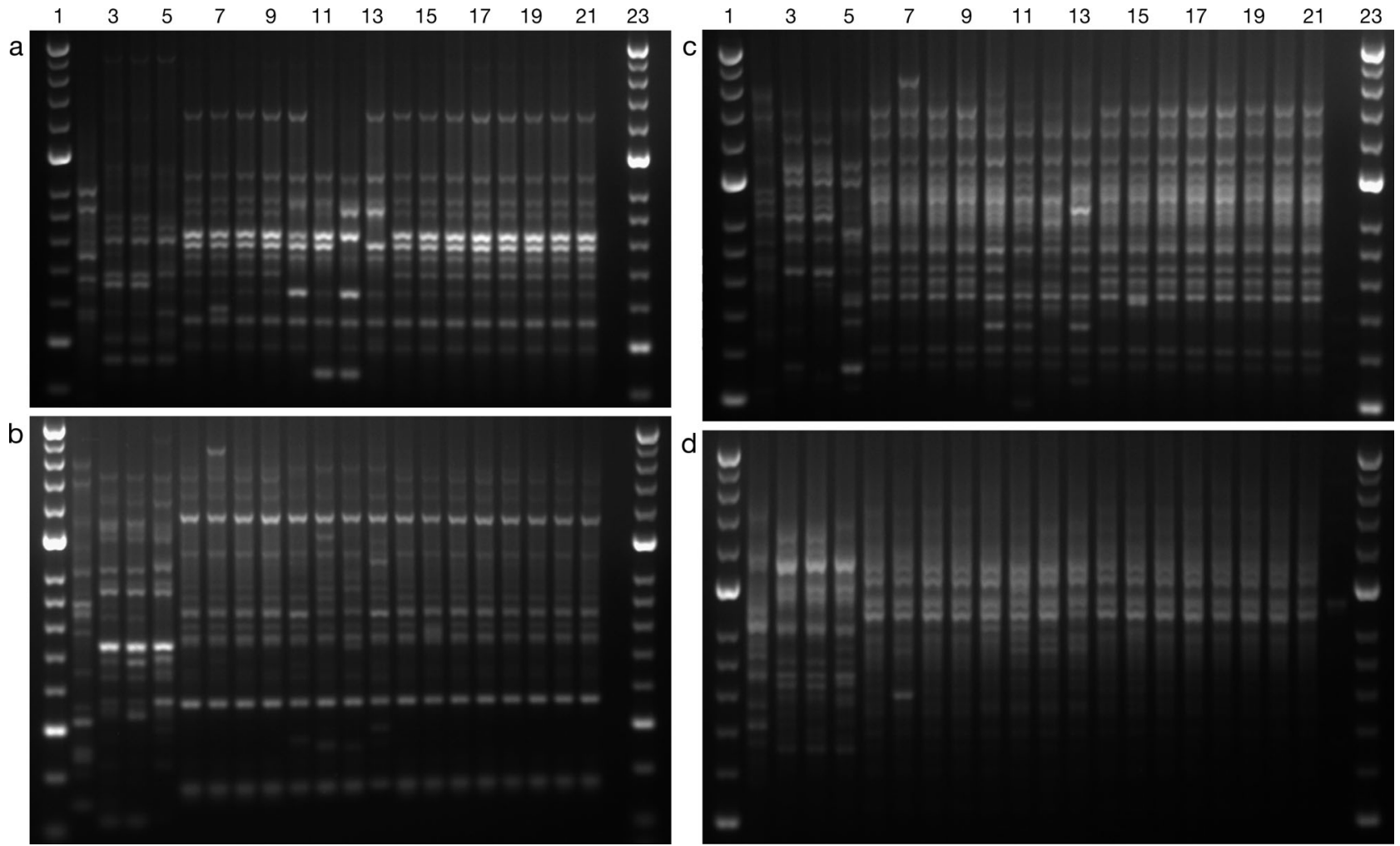

Fig. 4. Repetitive extragenic palindromic PCR amplification of DNA from 16 Veronaea botryosa isolates (Lanes 6-21). Genetic profiles were generated using (a) BOX, (b) ERIC I \& II, (c) ERIC II, and (d) GTG 5 primers (see Table 2). Lane designations are as follows: 1, 23 = Hyperladder 50 bp; $2=$ Cladophialophora spp. 812064; $3=$ Exophiala pisciphila 1009407; $4=$ Exophiala spp. 1006392; 5 = Exophiala spp. 1102537; $6=$ V. botryosa 608911; $7=$ V. botryosa 11-8844; $8=V$. botryosa 12M06899; $9=V$. botryosa $15 \mathrm{M} 00828 ; 10=V$. botryosa DI15-136; $11=V$. botryosa DI15-134; $12=V$. botryosa DI14-348; $13=V$. botryosa DI15-135; $14=V$. botryosa F15-3-4; $15=V$. botryosa F15-3-5; $16=V$. botryosa F15-3-6; $17=V$. botryosa F15-3-7; $18=V$. botryosa F15-3-8; $19=V$. botryosa F15-3-11; $20=V$. botryosa F15-3-12; $21=V$. botryosa F15-3-14; $22=$ no template control

0.08

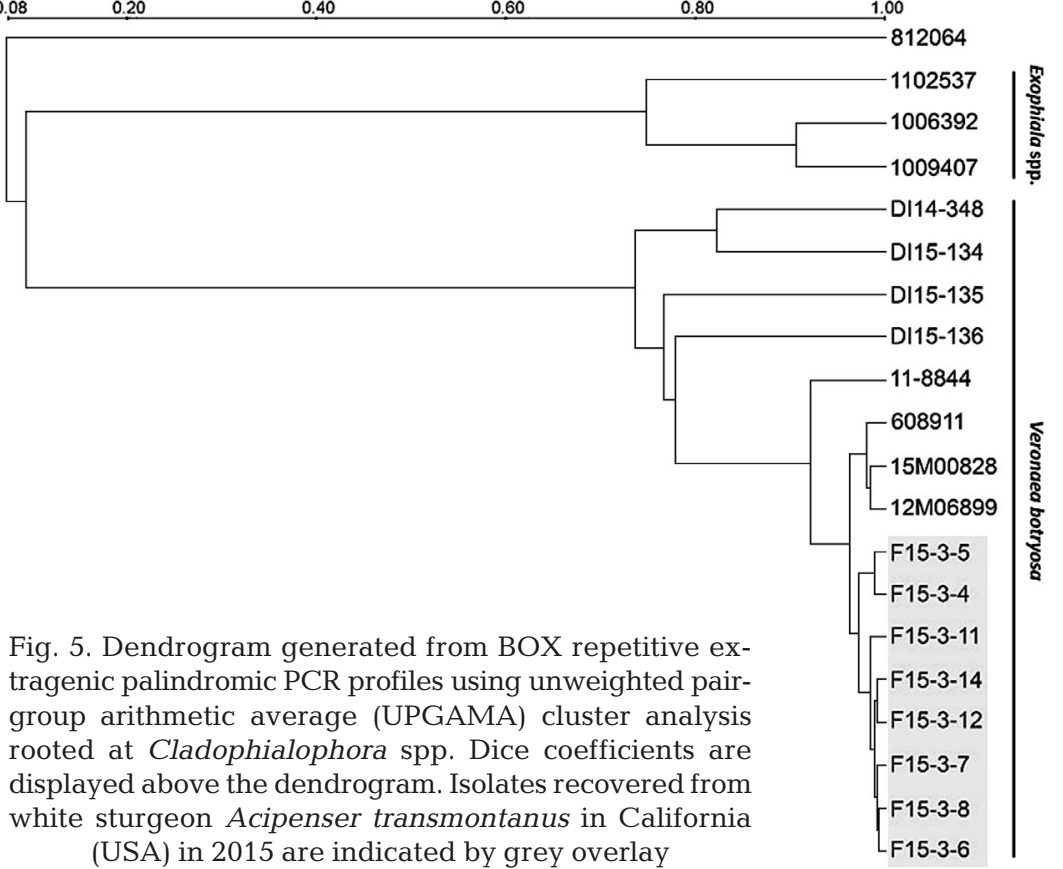

fungi or bacteria were recovered from liver or kidney, except for the liver of 1 fish challenged by immersion with mucus removal that cultured positive for $V$. botryosa, despite having no gross lesions. No fungal growth was observed on cultures from surviving fish from the oral challenge or from either immersion challenge (Table 4).

\section{DISCUSSION}

PCR-mediated genomic fingerprinting is a reliable method for systematic classification and discrimination of microbial strains (Mehta et al. 2002, Abdollahzadeh \& Zolfaghari 2014). Not surprisingly, Veronaea botryosa isolates from California white sturgeon are highly similar, but differ slightly 
Table 4. Summary of mortality, morbidity, and isolation in white sturgeon Acipenser transmontanus controls or challenged treatments with Veronaea botryosa; na: not applicable

\begin{tabular}{|lccc|}
\hline Treatment & $\begin{array}{c}\text { Mortality } \\
\text { ratio }(\%)\end{array}$ & $\begin{array}{c}\text { Isolation ratio }(\%) \\
\text { In dead/moribund }\end{array}$ \\
& & & \\
& & & \\
Controls & & na & $0 / 10(0)$ \\
Intracoelomic injection & $0 / 60(0)$ & na & $0 / 10(0)$ \\
Intramuscular injection & $0 / 60(0)$ & na & $0 / 10(0)$ \\
Oral & $0 / 60(0)$ & na & $0 / 10(0)$ \\
Immersion & $0 / 60(0)$ & $0 / 1(0)$ & $0 / 10(0)$ \\
Immersion + mucus removal & $1 / 60(1.6)$ & & \\
Challenge models & \multicolumn{3}{c}{} \\
Intracoelomic injection & $2 / 60(3.3)$ & $2 / 2(100)$ & $10 / 10(100)$ \\
Intramuscular injection & $8 / 60(13.3)$ & $8 / 8(100)$ & $9 / 10(90)$ \\
Oral & $0 / 60(0)$ & na & $0 / 10(0)$ \\
Immersion & $1 / 60(1.6)$ & $0 / 1(0)$ & $0 / 10(0)$ \\
Immersion + mucus removal & $3 / 60(5)$ & $1 / 3(33.3)$ & $0 / 10(0)$ \\
& &
\end{tabular}

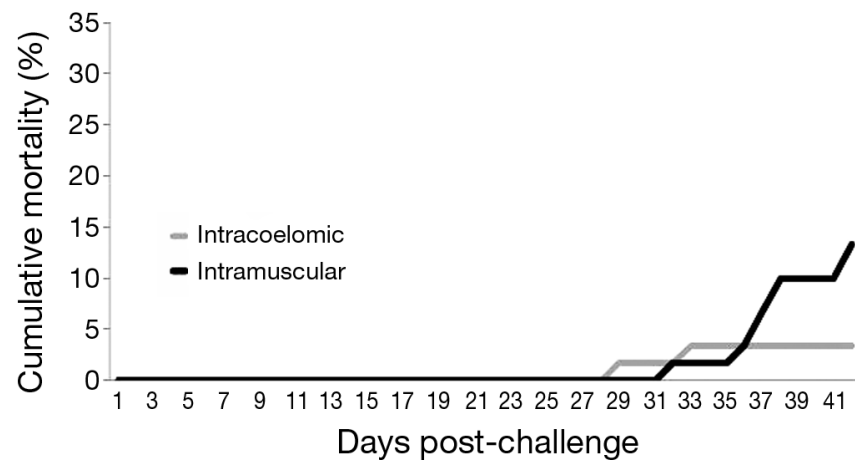

Fig. 6. Cumulative percent mortality of white sturgeon Acipenser transmontanus fingerlings challenged with Veronaea botryosa by intracoelomic or intramuscular injection (60 fish were infected per treatment)

from sea turtle and human isolates, suggesting the California sturgeon isolates represent a unique genotype. A dendrogram generated from BOX profiles places the $V$. botryosa sturgeon isolates in their own group, within a greater $V$. botryosa cluster and separate from the other phaeoid fungi evaluated (Fig. 4).

One limitation to this type of analysis is the identification of electrophoretic or transillumination artifacts, such as slight differences in band position and light intensity, as genetic variations detected by the software, even when visual analysis does not identify significant differences. As such, the cut-offs for establishing genetic differences are conservatively low. Still, the BOX profiles of $V$. botryosa isolates from different hosts and regions shared $>87 \%$ average similarity (range: $59.2-99.4 \%$ ), which is at or above the cut-off values for genotypic discrimination used in similar studies (Biddick et al. 2003, Keymer et al. 2009). Similar results were reported by Badali et al.
(2013), where the intraspecific variability of $18 \mathrm{~V}$. botryosa isolates from clinical and environmental sources was studied using amplified fragment length polymorphisms. A $V$. botryosa cluster containing strains with similarities of more than $75 \%$ was reported. No clear differentiation between clinical and environmental strains was observed (Badali et al. 2013), although none of the isolates was obtained from aquatic hosts or environments. Future research may benefit from other genotyping methods that provide a higher degree of resolution.

Infection by $V$. botryosa is prevalent in cultured, sexually mature white sturgeon, particularly at water temperatures above $18^{\circ} \mathrm{C}$. The use of mature females in experimental challenges is logistically challenging due to the high economic value of individual fish, as well as husbandry requirements associated with their large size. However, results indicate that white sturgeon fingerlings provide a suitable model for the study of systemic $V$. botryosa induced phaeohyphomycosis. Furthermore, limited data are available regarding controlled infectivity challenges of dematiaceous molds in fish (Otis et al. 1985, Rehulka et al. 2016). Otis et al. (1985) performed experimental inoculations of Exophiala salmonis in juvenile rainbow trout Oncorhynchus mykiss (formerly Salmo gairdneri) using IC injection routes and doses similar to those used in this study. However, no mortality was observed after $12 \mathrm{~d}$, and no fungus was recovered from the challenged fish. In contrast, E. pisciphila isolated from cardinal tetras Paracheirodon axelrodi produced mortalities of 60 and $80 \%$ in naïve common carp Cyprinus carpio injected with $\sim 10^{3}$ spores via IM and IC routes, respectively. Clinical signs were consistent with those observed in naturally infected fish (Řehulka et al. 2016).

In addition to IM and IC injection, immersion and oral challenges were conducted to approximate potential routes of natural infection and interaction with host innate defenses. The death of a fish challenged by immersion with mucus removal and re-isolation of $V$. botryosa from its liver suggests that abraded skin could provide a portal of entry and that mucus plays a defensive role in white sturgeon against fungal invasion. The mucus cuticle and its innate immune components help protect against infection by bacteria and yeast in fish (Tsutsui et al. 2007, Subramanian et al. 2008, Bragadeeswaran et al. 2011). 


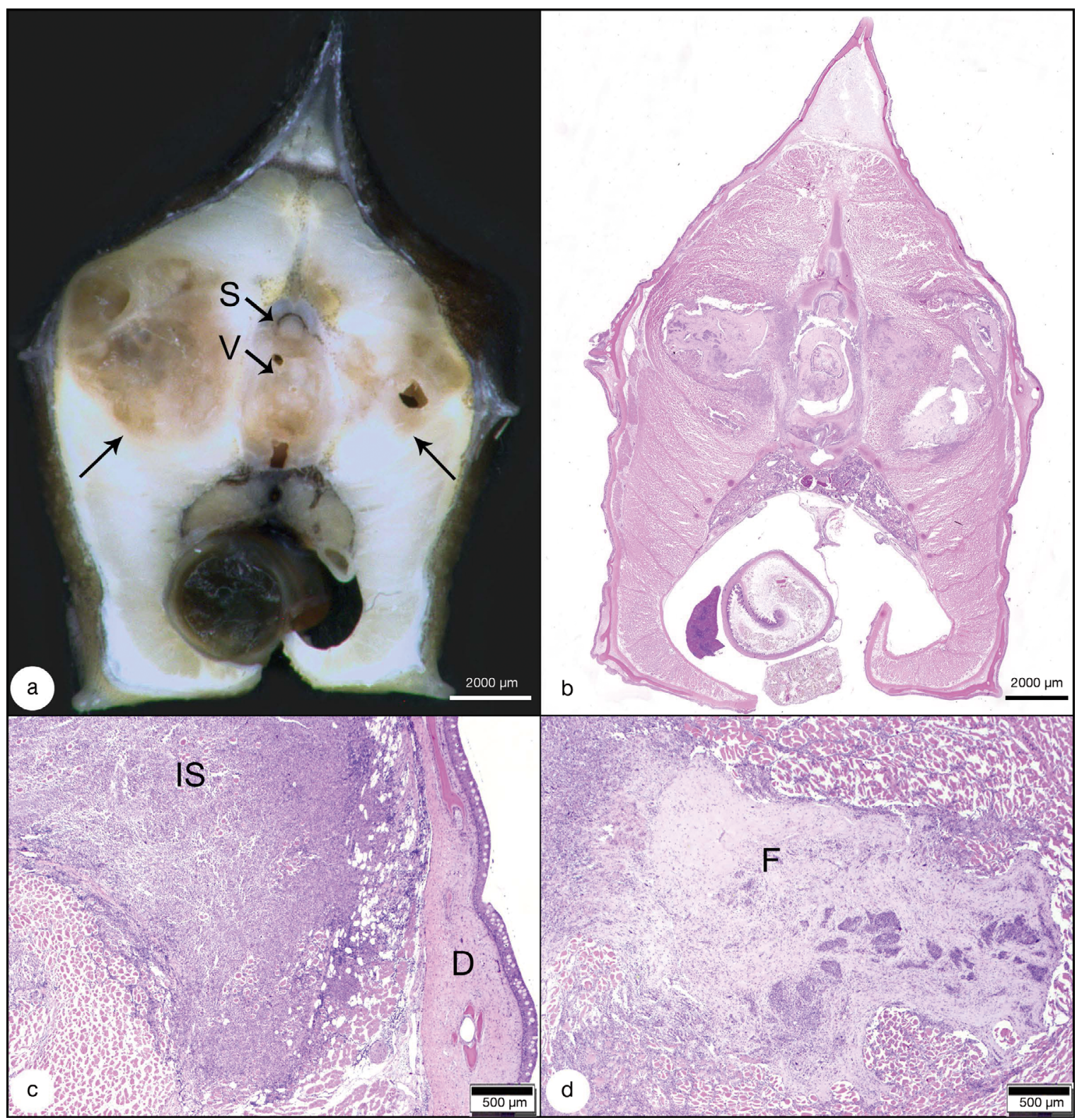

Fig. 7. Gross and subgross intramuscular injection site lesions (transverse sections) in moribund white sturgeon Acipenser transmontanus challenged with Veronaea botryosa. (a) Injection sites in expaxial muscle were irregular, pale brown, and often cavitated (arrows). Inflammatory exudate and hyphae enveloped the vertebral column (V) and destroyed the notochord. Exudate also filled the spinal canal and hyphae infiltrated the spinal cord (S). (b) Subgross image of a histological section showing similar changes. There was no infiltration of the coelomic cavity in this fish. (c,d) Injection site lesions (IS) replaced extensive areas of muscle and impinged on the dermis (D). The granulomatous inflammatory exudates were typical of fungal infection, predominated by macrophages, with small numbers of peripheral lymphocytes and granulocytes that radiated outward, isolating small groups of myofibers. Some lesions were dominated by fibrosis (F), suggesting lesion resolution

Results also indicate that both the IM and IC injection routes provide an easy and effective method to administer consistent challenge doses of suspended fungus, although injection challenges circumvent innate immune defenses in the skin, gills, and other mucosal surfaces. However, injection with $10^{4} \mathrm{CFU}$ fish $^{-1}$ produced a pattern of chronic mortality consis- tent with that seen under typical culture conditions, particularly above $18^{\circ} \mathrm{C}$ (Fig. 4). Industry practices, such as coeliotomy to assess egg maturity, might contribute to the implantation of fungal spores from the environment. In these cases, the IC route more accurately reproduces natural infection and provides an ideal model. Similarly, trauma-induced skin lesions 


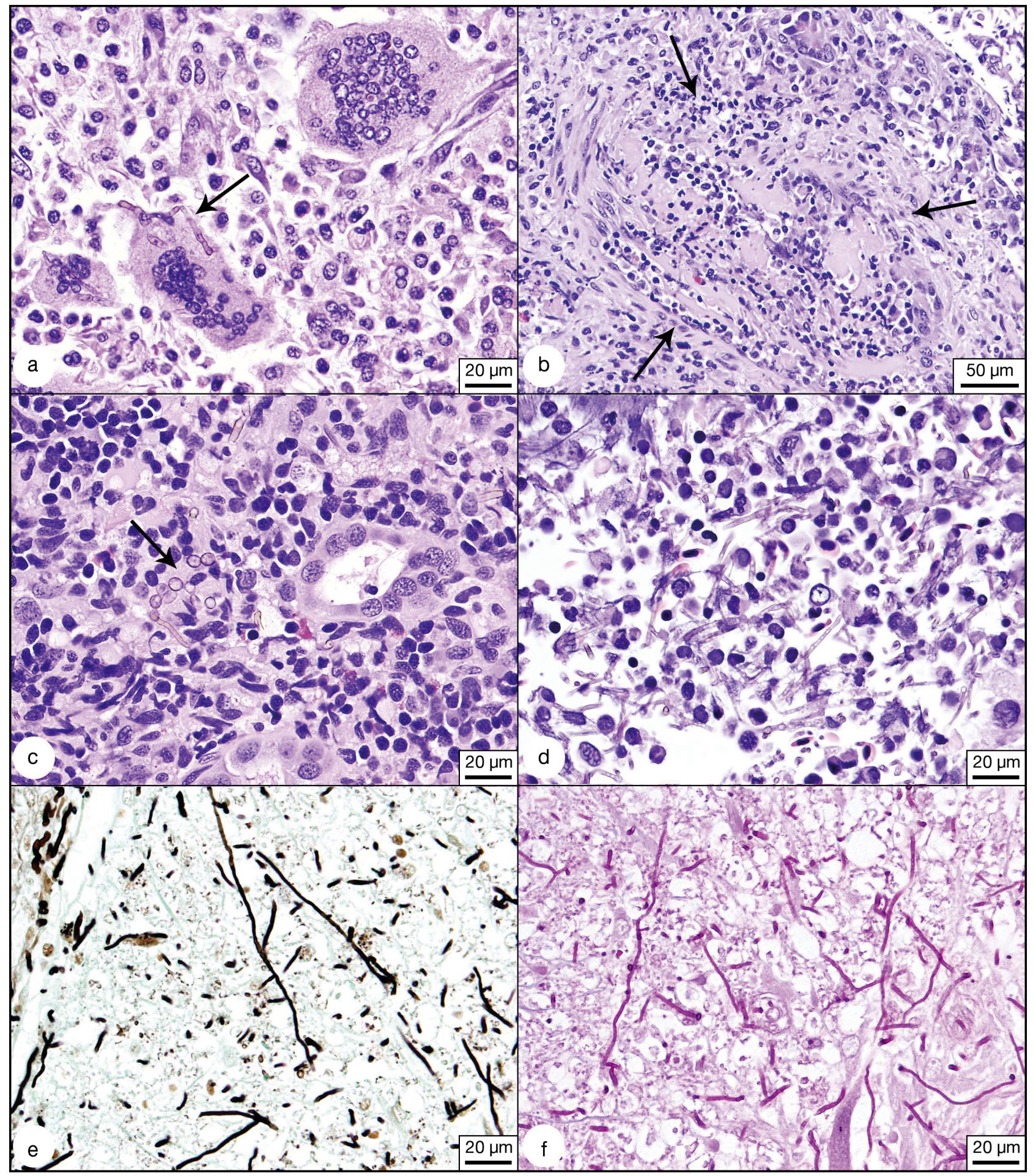

Fig. 8. Histological changes in laboratory-challenged white sturgeon Acipenser transmontanus. (a) Muscle lesion composed of sheets of macrophages with scattered multinucleated giant cells containing bronze hyphal fragments (arrow). (b) Thrombosed artery containing a mixture of fibrin, mononuclear inflammatory cells, and hyphae. Remnants of the necrotic arterial wall are indicated by arrows. (c,d) Morphology of the hyphae varied. In more chronic lesions (c), particularly within multinucleated giant cells, hyphae often had short plump segments that tapered adjacent to septa, and occasional globose swellings (arrow). In actively spreading lesions with large numbers of organisms (d), most hyphae had 3-5 $\mu$, thin, parallel walls, with less frequent septation and acute angle branching. (e,f) Hyphae were often pale staining and inconspicuous with H\&E stains and were more readily visualized with Gomori methenamine silver (e) and periodic acid-Schiff (f) stains 
and others associated with viral agents, like AciHV-2 (Watson et al. 1995, Soto et al. 2017), might promote fungal invasion of sub-epithelial tissues in compromised fish. In these cases, the IM injection route provides a suitable model of infection.

Microscopic findings were consistent with those of natural infection reported by Steckler et al. (2014). Angioinvasion appears important to dissemination of the agent, and in some lesions, significant tissue damage can result from infarction, rather than from direct effects of the fungus. While splenic and hepatic lesions likely resulted from hematogenous seeding, kidney lesions could be the result of direct extension from affected muscle. Following IM injection, hyphae and inflammatory cell numbers were highest on the margins of spreading lesions, while fibrosis occurred centrally. Lesions in coelomic organs were inconsistent between individual tissues and fish, even within the same challenge groups. As a result of this and the small sample size, no conclusions were made regarding lesion distribution and development between the IM and IC challenge groups. No morphologic features of the fungus were observed that might aid in the differentiation of $V$. botryosa from other pigmented fungi in tissue sections.

The oral and immersion methods more closely resemble natural routes of infection, as the fungus must overcome innate defenses. However, these exposure methods produced no mortalities, and fungus was not recovered from survivors in these groups. These findings suggest that $V$. botryosa is largely an opportunist, requiring a compromised host to initiate infection. However, it is difficult to ensure that all fish are given the same dose using the different exposure routes. In the oral challenge, numbers of $V$. botryosa reaching the stomach were not quantified, but much of the fungal dose was likely flushed away when fish were placed back into water. In this regard, challenge by gastric gavage is warranted to investigate uptake of spores by the gastrointestinal tract. To our knowledge, this route has not been explored in fish with respect to fungal infections.

Environmental conditions, such as water temperature, play a critical role in the development of innate and adaptive immune responses in fish, as well as the ability of certain pathogens to produce disease (Hrubec et al. 1996, Watts et al. 2001, Soto et al. 2012). White sturgeon are subjected to a range of temperatures, particularly in aquaculture, where higher temperatures accelerate growth, decreasing time to reproductive maturity and caviar production. However, little is known concerning the effects of temperature on immune responsiveness and subsequent impacts on disease susceptibility or the success of vaccination and other prophylactic measures in this species. Stressors, such as transport, suboptimal environmental conditions, and chlorine exposure, are suspected to have precipitated viral and bacterial co-infections in cultured shortnose sturgeon Acipenser brevirostrum (L.) and white sturgeon (La Patra et al. 2014, Soto et al. 2017). Additionally, differential expression of virulence factors in some fungal species are dependent on temperature (Wang \& Szaniszlo 2000, Keeratijarut et al. 2015); thus, future studies investigating the presence and expression of virulence factors in $V$. botryosa under different environmental conditions are warranted.

In conclusion, our findings indicate that $V$. botryosa isolates from cultured California white sturgeon represent a clonal group within a larger cluster of $V$. botryosa isolates from other hosts. Additionally, fingerlings injected by IM and IC routes at $18^{\circ} \mathrm{C}$ can serve as useful models of systemic infection. Further investigations into interactions between environmental-, host-, and pathogen-related factors conducive to infection are justified and essential to the development of prophylactic, therapeutic, and biosecurity regimens aimed at reducing losses from 'fluid belly' and improving profitability in sturgeon aquaculture facilities in the western USA.

Acknowledgements. We thank Dr. Brian A. Stacy from the National Marine Fisheries Service, National Oceanic and Atmospheric Administration, University of Florida (duty station), Gainesville, FL, USA, for sharing some of the isolates used in this study. We also thank Sterling Caviar for donation of fish.

\section{LITERATURE CITED}

Abdollahzadeh J, Zolfaghari S (2014) Efficiency of rep-PCR fingerprinting as a useful technique for molecular typing of plant pathogenic fungal species: Botryosphaeriaceae species as a case study. FEMS Microbiol Lett 361: 144-157

* Badali H, Yazdanparast SA, Bonifaz A, Mousavi B, de Hoog GS, Klaassen CH, Meis JF (2013) Veronaea botryosa: molecular identification with amplified fragment length polymorphism (AFLP) and in vitro antifungal susceptibility. Mycopathologia 175:505-513

Biddick R, Spilker T, Martin A, LiPuma JJ (2003) Evidence of transmission of Burkholderia cepacia, Burkholderia multivorans and Burkholderia dolosa among persons with cystic fibrosis. FEMS Microbiol Lett 228:57-62

Bonifaz A, Davoudi MM, de Hoog GS, Padilla-Desgarennes C and others (2013) Severe disseminated phaeohyphomycosis in an immunocompetent patient caused by Veronaea botryosa. Mycopathologia 175:497-503

Bragadeeswaran S, Priyadharshini S, Prabhu K, Rani SR (2011) Antimicrobial and hemolytic activity of fish epidermal mucus Cynoglossus arel and Arius caelatus. Asian Pac J Trop Med 4:305-309 
Chou L, Griffin MJ, Fraites T, Ware C and others (2014) Phenotypic and genotypic heterogeneity among Streptococcus iniae isolates recovered from cultured and wild fish in North America, Central America and the Caribbean Islands. J Aquat Anim Health 26:263-271

de Hoog GS, Vicente VA, Najafzadeh MJ, Harrak MJ, Badali H, Seyedmousavi S (2011) Waterborne Exophiala species causing disease in cold-blooded animals. Persoonia 27:46-72

Donnelly K, Waltzek TB, Wellehan JFX Jr, Sutton DA, Wiederhold NP, Stacy BA (2015) Phaeohyphomycosis resulting in obstructive tracheitis in three green sea turtles Chelonia mydas stranded along the Florida coast. Dis Aquat Org 113:257-262

Glass NL, Donaldson GC (1995) Development of primer sets designed for use with the PCR to amplify conserved genes from filamentous ascomycetes. Appl Environ Microbiol 61:1323-1330

Griffin MJ, Quiniou SM, Cody T, Tabuchi M and others (2013) Comparative analysis of Edwardsiella isolates from fish in the eastern United States identifies two distinct genetic taxa amongst organisms phenotypically classified as E. tarda. Vet Microbiol 165:358-372

*Hosoya T, Hanafusa Y, Kudo T, Tamukai K, Une Y (2015) First report of Veronaea botryosa as a causal agent of chromomycosis in frogs. Med Mycol 53:369-377

Hrubec TC, Robertson JL, Smith SA, Tinker MK (1996) The effect of temperature and water quality on antibody response to Aeromonas salmonicida in sunshine bass (Morone chrysops $\times$ Morone saxatilis). Vet Immunol Immunopathol 50:157-166

Huelsenbeck JP, Ronquist F (2001) MRBAYES: Bayesian inference of phylogeny. Bioinformatics 17:754-755

Kearse M, Moir R, Wilson A, Stones-Havas S and others (2012) Geneious Basic: an integrated and extendable desktop software platform for the organization and analysis of sequence data. Bioinformatics 28:1647-1649

Keeratijarut A, Lohnoo T, Rujirawat T, Yingyong W and others (2015) The immunoreactive exo-1,3- $\beta$-glucanase from the pathogenic oomycete Pythium insidiosum is temperature regulated and exhibits glycoside hydrolase activity. PLOS ONE 10:e0135239

Keymer DP, Lam LH, Boehm AB (2009) Biogeographic patterns in genomic diversity among a large collection of Vibrio cholerae isolates. Appl Environ Microbiol 75:1658-1666

Kimura M (1980) A simple method for estimating evolutionary rates of base substitutions through comparative studies of nucleotide sequences. J Mol Evol 16:111-120

* LaPatra SE, Groff JM, Keith I, Hogans WE, Groman D (2014) Case report: concurrent herpesviral and presumptive iridoviral infection associated with disease in cultured shortnose sturgeon, Acipenser brevirostrum (L.), from the Atlantic coast of Canada. J Fish Dis 37:141-147

Mehta A, Mehta YR, Rosato YB (2002) ERIC- and REP-PCR amplify non-repetitive fragments from the genome of Drechslera avenae and Stemphylium solani. FEMS Microbiol Lett 211:51-55

Monterey Bay Aquarium (2016) White sturgeon. www. montereybayaquarium.org/animal-guide/fishes/whitesturgeon (accessed 9 March 2016)

O'Donnell K, Cigelnik E (1997) Two divergent intragenomic rDNA ITS2 types within a monophyletic lineage of the fungus Fusarium are nonorthologous. Mol Phylogenet Evol 7:103-116

Otis EJ, Wolke RE, Blazer VS (1985) Infection of Exophiala salmonis in Atlantic salmon (Salmo salar L.). J Wildl Dis 21:61-64
Pikitch EK, Doukakis P, Lauck L, Chakrabarty P, Erickson DL (2005) Status, trends and management of sturgeon and paddlefish fisheries. Fish Fish 6:233-265

Řehulka J, Kolařík M, Hubka V (2016) Disseminated infection due to Exophiala pisciphila in Cardinal tetra, Paracheirodon axelrodi. J Fish Dis (in press) doi:10.1111/ jfd. 12577

Ronquist F, Huelsenbeck JP (2003) MRBAYES 3: Bayesian phylogenetic inference under mixed models. Bioinformatics 19:1572-1574

Soto E, Abrams SB, Revan F (2012) Effects of temperature and salt concentration on Francisella noatunensis subsp. orientalis infections in Nile tilapia Oreochromis niloticus. Dis Aquat Org 101:217-223

Soto E, Richey C, Stevens B, Yun S and others (2017) Coinfection of Acipenserid herpesvirus 2 (AciHV-2) and Streptococcus iniae in cultured white sturgeon Acipenser transmontanus. Dis Aquat Org 124:11-20

Steckler NK, Yanong RPE, Pouder DB, Nyaoke A and others (2014) New disease records for hatchery-reared sturgeon. II. Phaeohyphomycosis due to Veronaea botryosa. Dis Aquat Org 111:229-238

Subramanian S, Ross NW, MacKinnon SL (2008) Comparison of antimicrobial activity in the epidermal mucus extracts of fish. Comp Biochem Physiol B Biochem Mol Biol 150: 85-92

* Tamura K, Stecher G, Peterson D, Filipski A, Kumar S (2013) MEGA6: Molecular Evolutionary Genetics Analysis version 6.0. Mol Biol Evol 30:2725-2729

Thompson JD, Higgins DG, Gibson TJ (1994) CLUSTAL W: improving the sensitivity of progressive multiple sequence alignment through sequence weighting, position-specific gap penalties and weight matrix choice. Nucleic Acids Res 22:4673-4680

Trifonov VA, Romanenko SS, Beklemisheva VR, Biltueva LS and others (2016) Evolutionary plasticity of acipenseriform genomes. Chromosoma 125:661-668

Tsutsui S, Iwamoto K, Nakamura O, Watanabe T (2007) Yeast-binding C-type lectin with opsonic activity from conger eel (Conger myriaster) skin mucus. Mol Immunol 44:691-702

Versalovic J, Koeuth T, Lupski JR (1991) Distribution of repetitive DNA sequences in eubacteria and application to fingerprinting of bacterial genomes. Nucleic Acids Res 19:6823-6831

Versalovic J, Schneider M, De Bruijn FJ, Lupski JR (1994) Genomic fingerprinting of bacteria using repetitive sequence-based polymerase chain reaction. Methods Mol Cell Biol 5:25-40

W Wang Z, Szaniszlo PJ (2000) WdCHS3, a gene that encodes a class III chitin synthase in Wangiella (Exophiala) dermatitidis, is expressed differentially under stress conditions. J Bacteriol 182:874-881

*Watson LR, Yun SC, Groff JM, Hedrick RP (1995) Characteristics and pathogenicity of a novel herpesvirus isolated from adult and subadult white sturgeon Acipenser transmontanus. Dis Aquat Org 22:199-210

*Watts M, Munday BL, Burke CM (2001) Immune responses of teleost fish. Aust Vet J 79:570-574

*Wei QW, Zou Y, Li P, Li L (2011) Sturgeon aquaculture in China: progress, strategies and prospects assessed on the basis of nation-wide surveys (2007-2009). J Appl Ichthyol 27:162-168

* Zhu CY, Yang YP, Sheng P, Li W, Huang WM, Fan YM (2015) Cutaneous chromoblastomycosis caused by Veronaea botryosa in a patient with pemphigus vulgaris and review of published reports. Mycopathologia 180:123-129 